\section{Nível de comparabilidade dos ativos intangíveis das companhias brasileiras do segmento de energia elétrica listadas na B3.}

\author{
Ana Karoline Ventura \\ UFSC - Universidade Federal de Santa Catarina \\ anakventura@gmail.com \\ Juliane Pacheco \\ UFSC - Universidade Federal de Santa Catarina \\ pac.juliane@gmail.com \\ Suliani Rover \\ UFSC - Universidade Federal de Santa Catarina \\ sulianirover@gmail.com
}

\title{
Resumo
}

Uma das vantagens da adoção das normas internacionais de contabilidade é a possibilidade de fazer comparações entre diversas empresas. Com isso, o objetivo do estudo consiste em verificar o nível de comparabilidade dos ativos intangíveis das empresas do segmento elétrico que estão listadas na Brasil, Bolsa, Balcão (B3). Para tanto, foram analisados critérios de reconhecimento, mensuração e evidenciação de ativos intangíveis divulgados no balanço patrimonial e nas notas explicativas. Para fins de análises, as empresas foram divididas conforme suas atividades principais: geração; transmissão; distribuição e geração; e transmissão e distribuição. A pesquisa foi realizada com uma amostra de 43 empresas no período de 2013 a 2016. Quanto aos itens analisados nos documentos, investigou-se um item de reconhecimento, três de mensuração e cinco itens principais de evidenciação. Para as análises foram utilizadas estatísticas descritivas e, com o intuito de verificar a comparabilidade, o índice de Herfindahl $(\mathrm{H})$. Os resultados apontaram que os valores contabilizados no intangível são discrepantes, e todas possuíam concessões. Quando à comparabilidade, 0 índice $\mathrm{H}$ para o método de avaliação dos intangíveis foi em torno de 0,50 nos anos analisados, indicando que ao escolher duas empresas aleatoriamente a probabilidade de adotarem o mesmo método é de $50 \%$. Já para o teste de recuperabilidade, se mostrou superior a $0,50 \mathrm{em}$ todos os anos, sendo que em 2013 atingiu 0,646. Assim, conclui-se que as empresas analisadas apresentaram índices que indicam comparabilidade mediana no período investigado, indicando que não há uma padronização nas escolhas contábeis aplicadas pelas empresas.

Palavras-chave: Comparabilidade. Ativo intangível. Energia Elétrica.

ISSN: $1984-6266$

Recebimento:

$12 / 03 / 2018$

Aprovação:

$24 / 04 / 2019$

Editor responsável pela aprovação do artigo:

Dr. Flaviano Costa

Editor responsável pela edição do artigo:

Dr. Flaviano Costa

Avaliado pelo sistema:

Double Blind Review

A reprodução dos artigos, total ou parcial, pode ser feita desde que citada a fonte.

PROGRAMA DE PÓS-GRADUAÇÃO EM CONTABILIDADE uFrr MESTRADO E DOUTORADO

DOI:

http://dx.doi.org/10.5380/rc\&c.v10i2.58369 


\title{
LEVEL OF COMPARABILITY OF INTANGIBLE ASSETS OF BRAZILIAN COMPANIES OF THE ELECTRICITY SEGMENT LISTED ON B3
}

\begin{abstract}
One of the advantages of adopting international accounting standards is the possibility of comparisons between different companies. Therefore, the aim of the study is to verify the level of comparability of intangible assets of companies in the electric segment that are listed on the B3. For this purpose, criteria for recognition, measurement and disclosure of intangible assets disclosed in the balance sheet and in the notes to the financial statements were analyzed. For analysis purposes, the companies were divided according to their main activities: generation; streaming; distribution and generation; and transmission and distribution. The research was carried out with a sample of 43 companies from 2013 to 2016. Regarding the items analyzed in the documents, an item of recognition, three measurement items and five main items of evidence were investigated. For the analyzes, descriptive statistics were used and, to verify the comparability, the Herfindahl index $(\mathrm{H})$. The results indicated that the amounts recorded in intangible assets were discrepant, and all had concessions. When comparing, the $\mathrm{H}$ index for the method of valuation of intangibles was around 0.50 in the analyzed years, indicating that when choosing two companies randomly the probability of adopting the same method is $50 \%$. For the recoverability test, it was higher than 0.50 in all years, and in 2013 it reached 0.646 . Thus, it can be concluded that the companies analyzed presented indices that indicate a median comparability in the period investigated, indicating that there is no standardization in the accounting choices applied by the companies.
\end{abstract}

Keywords: Comparability. Intangible assets. Electricity.

\section{Introdução}

Adesão das normas internacionais de contabilidade tem algumas vantagens, entre elas pode-se destacar a maior transparência das informações de diversas empresas e setores, harmonização das informações contábeis, assim possibilitando comparações entre diferentes empresas, inclusive de países diferentes (Tavares, Gonçalves \& Niyama, 2010). Para Franco, Kothari e Verdi (2011) a possibilidade de comparabilidade é importante para pesquisadores, acadêmicos, investidores e empresários, pois com a possibilidade de comparabilidade as informações são mais refinadas e com maior qualidade.

Para Carmo, Ribeiro e Carvalho (2011), existem diversas razões para que haja diferentes sistemas contábeis entre os países, como ambiente social, econômico, legal e políticos. 0 sistema contábil que é adotado em um país é reflexo desses fatores. Cada país foi moldando os seus sistemas de acordo com as necessidades específicas da sociedade (Carmo, Ribeiro \& Carvalho, 2011).

Segundo o documento emitido pela IFRS em 2017 existem 140 países que assumiram o uso das normas internacionais, sendo que em 126 é uma exigência para as empresas de capital aberto. No Brasil 0 processo de convergência se tornou obrigatório em 2010, isto foi possível após as normas internacionais serem criadas, lançadas para que então fosse iniciado um processo de convergência (Coelho, Campagnoni \& Rover, 2016).

Para regularização da divulgação dos ativos intangíveis, seu reconhecimento, e mensuração, tem-se internacionalmente a norma International Accounting Standards (IAS 38), que teve sua última atualização em maio de 2014. No Brasil, em 2010, foi publicado o pronunciamento técnico do Comitê de Pronunciamentos Contábeis 04 - Ativo Intangível (CPC 04 R1), que define como deve ser o tratamento dos ativos intangíveis, estabelece os critérios de reconhecimento, explica como mensurar e quais são as divulgações específicas dos ativos intangíveis. Além disso, em 2011 foi aprovada e divulgada a Interpretação Técnica ICPC 01 (R1) -

RC\&C - Revista Contabilidade e Controladoria, Curitiba, v. 10, n. 2, p. 58-75, mai./ago. 2018. 
Contratos de Concessão, correlata as normas internacionais International Financial Reporting Interpretations Committee 12 (IFRIC 12), na qual modificou a maneira de contabilizar os contratos de concessão, assim como as receitas proveniente deles.

O ICPC 01 R1 (2011) segrega os valores reconhecidos no ativo financeiro e intangível. 0 ativo financeiro é reconhecido a partir do momento que o concessionário tem o direito de receber caixa ou outros ativos financeiros, geralmente o contrato é executável por lei. Já o reconhecimento do ativo intangível ocorre conforme o direito de cobrar os usuários do serviço, porém não os valores são condicionados à utilização do serviço público, não gerando direito incondicional de receber caixa (Ferreira, Carmo, Moura \& Ribeiro, 2017).

De acordo com o CPC 04 R1(2010, p.6), "ativo intangível é um ativo não monetário identificável sem substância física", e para Kohler (1957) são ativos sem existência física cujo valor se limita pelo benefício e direito que sua posse confere ao proprietário.

Segundo Høegh-Krohn e Knivsflã (2000), o grande problema entorno dos ativos intangíveis é que eles podem ser de difícil identificação de seus benefícios econômicos futuros, o que pode gerar dificuldade entre as empresas evidenciarem esse tipo de ativo em seu balanço patrimonial.

Devido à característica do setor de utilidade pública de possuir intangíveis, visto que a principal atividade envolve contratos de concessões, principalmente no segmento de energia elétrica com a atividade de distribuição, além de representar uma parcela relevante das empresas de capital aberto do mercado brasileiro, este estudo tem como enfoque as companhias pertencentes a este subsetor. Diante disso, questiona-se como o segmento de energia elétrica trata seus ativos intangíveis, levantando a seguinte questão de pesquisa: Qual o nível de comparabilidade dos ativos intangíveis das companhias brasileiras do segmento de energia elétrica listadas na B3 no período de 2013 a 2016 ?

O principal objetivo desta pesquisa é verificar o nível de comparabilidade dos ativos intangíveis das empresas do segmento elétrico que estão listadas na B3 no período de 2013 a 2016. Foi escolhido este subsetor da economia brasileira por ser um segmento com uma grande expressividade na bolsa de valores e na economia brasileira, sendo o segundo maior na B3, com 60 empresas em 2017. A comparabilidade é o enfoque da pesquisa por sua importância para a contabilidade. O foco são os ativos intangíveis por estarem cada vez mais presentes no cotidiano das empresas, principalmente após 2010.

\section{Referencial Teórico}

\subsection{Ativos intangíveis}

Os ativos são recursos controlados por uma entidade que geram benefícios presentes ou futuros. Esses ativos devem ter algumas características para serem reconhecidos, como serem relevantes; mensuráveis e terem valor preciso, conforme o CPC 00 - Estrutura Conceitual para Elaboração e Divulgação de Relatório Contábil-Financeiro (R1, 2011).

Esse ativo pode ter recurso físico ou não, desde que estejam em controle da entidade e que ela o utilize nos produtos e serviços destinados aos clientes, de forma que produzam benefícios econômicos futuros (Perez \& Famá, 2006). Quando esse recurso não é físico, é classificado como intangível.

0 grupo de ativo intangível foi incluído no balanço patrimonial após a alteração na lei $n^{0} 6.404$ (1976), feitas pelas Leis n. 11.638 (2007) e 11.941 (2009). Esse grupo já era uma exigência para as companhias abertas, devido a uma deliberação da Comissão de Valores Mobiliários (CVM). $O$ ativo intangível foi enquadrado no grupo de ativos não circulantes. A Lei $n^{0} 6.404$ (1976) em seu artigo 179 inciso VI determina que seja classificado no intangível "os direitos que tenham por objeto bens incorpóreos destinados a manutenção da companhia ou exercidos com essa finalidade, inclusive o fundo de comercio adquirido". 
Para geração de valor de uma empresa os recursos intangíveis são essenciais, inclusive dependendo do setor e segmento pode haver intangíveis específicos que ajudem na valorização (Colauto, Nascimento, Avelino \& Bispo, 2009). Por exemplo, as marcas para empresas do consumo não cíclico, e as pesquisas e desenvolvimento em empresas farmacêuticas (Kayo, Kimura, Martin, \& Nakamura, 2006).

0 ativo intangível de uma empresa não necessariamente é o valor expresso no balanço patrimonial, visto que para sua ativação o bem precisa obedecer aos critérios citados anteriormente, e caso o bem seja gerado internamente precisa cumprir os critérios de desenvolvimento do CPC 04 R1 (2010), como por exemplo, a viabilidade técnica e intenção de concluir para usar ou vender o ativo intangível e a mensuração dos gastos atribuíveis devem ser de maneira confiável. Conforme o estudo de Santos (2015) esses intangíveis não evidenciados bem como a representatividade do intangível podem influenciar no valor de mercado das companhias.

Em 2011 houve a mudança da contabilização das concessões, conforme publicação do ICPC 01 R1 (2011), de modo que empresas que exploravam serviços públicos, por exemplo, exploração de rodovias e energia elétrica, modificaram a estrutura do seu ativo financeiro, imobilizado e intangível. Como exposto pelo estudo de caso na empresa Light Serviços de Eletricidade S.A., visto que quando houve a adoção da ICPC 01 evidenciou a redução do imobilizado a zero e aumento dos ativos financeiros e intangíveis (Scalzer, 2013).

Sendo o intangível, contratos de concessão, que conforme Kloeppel, Klann e Zittei (2013) são direitos contratuais na qual são concedidos a terceiros com intuito de exploração dos recursos naturais e públicos.

O setor de utilidade pública possui empresas que exploram os recursos naturais e públicos, as energias elétricas, visto que o governo concede a empresas privadas a responsabilidade de prestar um serviço público (Ferreira et al., 2017). Deste modo, o intangível dessas companhias é composto basicamente por concessões, e estudar a comparabilidade dessas empresas é importante para verificar como está a transparência, de maneira a aumentar a confiabilidade do investidor (Kloeppel et al., 2013).

\subsection{Comparabilidade}

Para Franco et al. (2011) duas empresas têm sistemas contábeis comparáveis, se produzirem demonstrações contábeis e financeiras semelhantes. Para que as informações acerca de determinado evento contábil possam ser comparadas, elas precisam ter bases semelhantes, os usuários das demonstrações necessitam e exigem cada vez mais qualidade de informações (Coelho et al., 2016). Para Araújo, Souza e Lemes (2015), as demonstrações contábeis para serem comparáveis precisam independente do país, da empresa ou do ano que sejam elaboradas e tenham as mesmas bases normativas, sendo possível a comparabilidade entre elas.

O CPC 00 R1 (2011), que é o pronunciamento contábil básico, diz que os usuários devem conseguir comparar as demonstrações contábeis, tanto da mesma entidade ao longo do tempo, como de diferentes entidades, com o objetivo de encontrar tendências nas suas posições patrimoniais e financeiras, e acompanhar os desempenho e mutações financeiras.

O CPC 00 R1 (2011) também traz que existem características qualitativas fundamentais: relevância e a representação fidedigna, e características qualitativas de melhorias: comparabilidade, verificabilidade, tempestividade e compreensibilidade. Essas últimas tornam a informação contábil relevante. Com relação à comparabilidade o CPC 00 R1 (2011, p. 17) define como "a característica qualitativa que permite que os usuários identifiquem e compreendam similaridades dos itens e diferenças entre eles. Diferentemente de outras características qualitativas, a comparabilidade não está relacionada com um único item. A comparação requer no mínimo dois itens".

Para o cálculo da comparabilidade existem alguns índices, por exemplo, o índice T, índice I, índice V, índice $\mathrm{C}$ que podem ser utilizados. Porém, optou-se por utilizar o índice de Herfindahl, conhecido como $\mathrm{H}$, de 
Van Der Tas (1988), o qual busca verificar a probabilidade de selecionar de forma aleatória as empresas de um mesmo país que utilizam o mesmo método contábil (Taplin, 2004). Além disso, é um índice que compara empresas nacionais, considera a não divulgação e o número de empresas pesquisas (Cole, Branson \& Breesch, 2008; Cole, Branson \& Breesch 2009).

\subsection{Estudos similares}

Pesquisas sobre ativos intangíveis e sobre comparabilidade ajudaram a construir a fundamentação teórica desta pesquisa. A Figura 1 traz pesquisas similares ao do presente estudo.

Figura 1: Pesquisas similares

\begin{tabular}{|c|c|c|}
\hline Autor (Ano) & Objetivo & Resultados \\
\hline $\begin{array}{l}\text { Doni, Taplin e Verona } \\
(2016)\end{array}$ & $\begin{array}{l}\text { Os autores forneceram um julgamento sobre a } \\
\text { comparabilidade das demonstrações } \\
\text { financeiras preparadas de acordo com as IFRS } \\
\text { e US-GAAP. Foi utilizado um índice T } \\
\text { estruturado por } 13 \text { itens de comparabilidade em } \\
250 \text { empresas de cinco países (França, } \\
\text { Alemanha, Itália, Reino Unido e Estados Unidos } \\
\text { da América). }\end{array}$ & $\begin{array}{l}\text { As demonstrações financeiras das empresas } \\
\text { europeias convergem fortemente para o } \\
\text { "modelo de custos", com alto nível de } \\
\text { comparabilidade nacional e aumenta ao ser } \\
\text { incluído os Estados Unidos. Já em relação ao } \\
\text { teste de impairment, a comparabilidade não foi } \\
\text { alta, porém ao inserir os Estados Unidos não } \\
\text { houve significância. }\end{array}$ \\
\hline Souza e Lemes (2016) & $\begin{array}{l}\text { Identificaram o grau de comparabilidade das } \\
\text { escolhas contábeis na mensuração } \\
\text { subsequente de ativos imobilizados, de ativos } \\
\text { intangíveis e de propriedades para investimento } \\
\text { (PPI) de companhias abertas do Brasil, Chile e } \\
\text { Peru, além disso, também apuraram se } \\
\text { determinadas características das entidades } \\
\text { influenciam na escolha dos gestores pelo valor } \\
\text { justo. A comparabilidade foi medida por meio do } \\
\text { índice T e a identificação das variáveis } \\
\text { explicativas foi feita por meio de regressões, no } \\
\text { período 2009-2013. }\end{array}$ & $\begin{array}{l}\text { Os resultados demonstraram que o ativo } \\
\text { imobilizado aumentou a comparabilidade, já o } \\
\text { ativo intangível não houve aumento } \\
\text { considerável, enquanto o PPI não houve } \\
\text { aumento. Concluindo que a IFRS não garantiu } \\
\text { a comparabilidade. Por fim, quanto à escolha do } \\
\text { gestor, algumas características influenciaram, } \\
\text { como setor de atuação, país, remuneração dos } \\
\text { gestores, tamanho, endividamento e } \\
\text { rentabilidade. }\end{array}$ \\
\hline Coelho et al., (2016) & $\begin{array}{l}\text { Verificaram o nível de comparabilidade das } \\
\text { práticas contábeis de mensuração, avaliação e } \\
\text { evidenciação dos estoques das empresas } \\
\text { brasileiras do ramo varejista. Foi utilizado um } \\
\text { checklist e o índice de T de harmonia, proposto } \\
\text { por Tablin. }\end{array}$ & $\begin{array}{l}\text { As empresas buscaram apresentar as } \\
\text { demonstrações contábeis com maior } \\
\text { padronização. Quanto à prática de mensuração, } \\
\text { verificaram que cerca de } 50 \% \text { das empresas da } \\
\text { amostra mensuraram seus estoques pelo valor } \\
\text { realizável líquido, reconhecendo perdas } \\
\text { estimadas no período de } 2010 \text { e } 2015 \text {. }\end{array}$ \\
\hline $\begin{array}{l}\text { Souza, Botinha e Lemes } \\
\qquad(2016)\end{array}$ & $\begin{array}{l}\text { O estudo visou demonstrar aos usuários das } \\
\text { DC's se elas são equiparáveis quanto a } \\
\text { mensuração dos ativos intangíveis, entre as } \\
\text { entidades de um mesmo país e de países } \\
\text { diferentes. Foi utilizado um quadro de } \\
\text { mensuração adaptado de Souza, Silva e Costa } \\
\text { (2013), e após utilizado o índice de T (T index). }\end{array}$ & $\begin{array}{l}\text { Foi identificado uma comparabilidade média } \\
\text { entre os países estudados, e dentro de cada } \\
\text { país o Brasil teve uma comparabilidade superior } \\
\text { ao de Portugal. }\end{array}$ \\
\hline Reina, Reina \& Silva (2014) & $\begin{array}{l}\text { A pesquisa teve como objetivo analisar os níveis } \\
\text { de comparabilidade dos relatórios financeiros } \\
\text { das empresas com compõe o Índice Brasil } 50 \\
\text { após a adoção das normas internacionais. Foi } \\
\text { calculado a comparabilidade pelo índice T } \\
\text { index. }\end{array}$ & $\begin{array}{l}\text { O nível de comparabilidade médio para o CPC } \\
16 \text { Estoque foi de } 0,34 ; \text { CPC } 27 \text { Imobilizado } 0,9 ; \\
\text { CPC 04 Intangíveis } 0,92 ; \text { e CPC } 38 \\
\text { Instrumentos Financeiros, mantidos para venda } \\
0,15 \text {, mensurados por meio do resultado } 0,92 ; \\
\text { empréstimos e contas a receber } 0,98 ; \text { mantidos } \\
\text { para venda } 0,27 \text {; e derivativos } 0,58 \text {. }\end{array}$ \\
\hline
\end{tabular}




\begin{tabular}{|c|c|c|}
\hline Autor (Ano) & Objetivo & Resultados \\
\hline $\begin{array}{l}\text { Avelino, Pinheiro e } \\
\text { Lamounier (2012) }\end{array}$ & $\begin{array}{l}\text { O objetivo do estudo foi apresentar um índice de } \\
\text { evidenciação de informações compulsórias } \\
\text { sobre os ativos intangíveis de empresas listadas } \\
\text { no lbovespa, no ano de } 2010 \text {, observando os } \\
\text { critérios do CPC 04. Foram analisados } 17 \\
\text { quesitos e atribuídos notas para formar um } \\
\text { ranking. }\end{array}$ & $\begin{array}{l}\text { Observou-se que nenhuma das empresas } \\
\text { estudadas cumprem integralmente } 0 \text { que } \\
\text { estabelece a legislação em relação à divulgação } \\
\text { de informações contábeis. A informação menos } \\
\text { divulgada foi a de avaliação de vida útil dos } \\
\text { ativos. Constatou-se que não houve relação } \\
\text { entre o tamanho das empresas analisadas e o } \\
\text { nível de evidenciação das informações. }\end{array}$ \\
\hline $\begin{array}{l}\text { Moura, Fank e Varela } \\
\qquad(2012)\end{array}$ & $\begin{array}{l}\text { O estudo buscou verificar quais itens compõem } \\
\text { os ativos intangíveis evidenciados no balanço } \\
\text { patrimonial das empresas de energia elétrica, } \\
\text { participantes da BM\&Fbovespa. }\end{array}$ & $\begin{array}{l}\text { Concluíram que a evidenciação dos ativos } \\
\text { intangíveis foi melhorando. }\end{array}$ \\
\hline $\begin{array}{l}\text { Eckert, Mecca, Biasio e } \\
\text { Souza (2012) }\end{array}$ & $\begin{array}{l}\text { O objetivo de identificar os possíveis impactos } \\
\text { das alterações do deemed cost e do impairment } \\
\text { test nas demonstrações contábeis das } \\
\text { empresas de bens industriais gaúchas listadas } \\
\text { na Bovespa. A comparabilidade foi feita através } \\
\text { dos saldos contábeis de antes e depois das } \\
\text { alterações nas demonstrações contábeis. }\end{array}$ & $\begin{array}{l}\text { Os autores constataram que a adoção do } \\
\text { deemed cost aumentou significativamente o } \\
\text { ativo imobilizado, pela diferença entre o valor } \\
\text { residual e o valor justo desses ativos. } \\
\text { Constataram também que realização do } \\
\text { impairment test não impactou os resultados. Por } \\
\text { fim, concluem que houve alterações } \\
\text { significativas na forma como a mensuração e } \\
\text { reconhecimento dos ativos imobilizados foram } \\
\text { divulgados nas demonstrações contábeis. }\end{array}$ \\
\hline Tudor e Dragu (2010) & $\begin{array}{l}\text { O artigo buscou estudar o impacto das IFRS na } \\
\text { harmonização das práticas contábeis, medindo } \\
\text { o grau em que diferentes empresas da Europa } \\
\text { usam os mesmos métodos ao reportar seus } \\
\text { ativos intangíveis. Foi utilizado o índice } \\
\text { Herfindahl, a amostra foi composta por } 51 \\
\text { empresas listadas de cinco países europeus. }\end{array}$ & $\begin{array}{l}\text { Os resultados sugerem a influência das IFRS } \\
\text { sobre práticas contábeis, pois há evidências de } \\
\text { alto nível de harmonização para o } \\
\text { reconhecimento de intangíveis, uma tendência } \\
\text { à reconciliação para avaliação desses ativos, } \\
\text { bem como práticas comuns em matéria de } \\
\text { comprometimento. }\end{array}$ \\
\hline
\end{tabular}

Fonte: Elaborado pelos autores.

Observou-se nas pesquisas que as empresas estão padronizando suas demonstrações, com evolução ao decorrer dos anos, possibilitando uma melhor comparabilidade das informações tanto no Brasil, como em outros países. Com base nessas pesquisas, pode-se notar que a adoção das normas internacionais pode ter influenciado para que o nível de comparabilidade das demonstrações contábeis melhorasse ao longo do tempo.

\section{Procedimentos Metodológicos}

A pesquisa realizada caracteriza-se como descritiva com abordagem qualitativa e quantitativa. Para 0 estudo foram utilizadas as demonstrações financeiras (Balanço Patrimonial, e Notas explicativas) obtidas por meio do site da B3. Foi analisado o período de 2013 a 2016 das companhias do segmento de energia elétrica de capital aberto. A amostra de pesquisa compreende 43 empresas, conforme apresentado na Tabela 1.

Tabela 1: Amostra da pesquisa

\begin{tabular}{l|c}
\hline Passos para seleção da amostra & Quantidade \\
\hline Empresas do segmento elétrico da B3 & 60 \\
\hline (-) Eliminação (holdings) & -17 \\
\hline = Amostra da pesquisa & 43 \\
\hline
\end{tabular}

Fonte: Elaborada pelos autores. 
Foram eliminadas 17 empresas por serem holdings, ou seja, sua principal atividade é participações em outras sociedades. As empresas eliminadas são: AesElpa S.A, Alupar investimentos S.A, Andrade e Gutierrez Concessões S.A, Bonaire participações S.A, Cemig, centrais elétricas do brasil S.A(Eletrobrás), Centrais elétricas de Santa Catarina S.A, Cia Celg de participações- CELGPAR, Cia Energética de Brasília, CPFL Energia S.A, Eletrobrás participações S.A (Eletropar), Energisa S.A, Equatorial Energia S.A, Light S.A, Neoenergia S.A, Rede Energia S.A, Uptick Participações S.A.

Nas empresas de energia elétrica, suas atividades principais podem ser divididas entre: geração, transmissão e distribuição de energia elétrica, conforme apresenta a Figura 2.

Figura 2: Lista de empresas analisadas de acordo com a atividade principal

\begin{tabular}{|c|c|c|}
\hline Atividade Principal & Sigla & Razão Social \\
\hline \multirow{15}{*}{ Geração } & AES TIETE & Aes Tietê Energia S.A \\
\hline & AFLUENTE & Afluente Geração De Energia Elétrica S.A \\
\hline & CESP & Cia Energética De São Paulo \\
\hline & CPFL RENOVA & CPFL Energias Renováveis S.A \\
\hline & CPFL GERAÇÃO & CPFL Geração de Energia S.A \\
\hline & EMAE & Empresa Metrop. Aguas Energia S.A \\
\hline & ENEVA & Eneva S.A \\
\hline & ENGIE & Engie Brasil Energia S.A \\
\hline & INVESTCO & Investco S.A \\
\hline & ITAPEBI & Itapebi Geração De Energia S.A \\
\hline & PROMAN & Produtores Energet.De Manso S.A. \\
\hline & RENOVA & Renova Energia S.A \\
\hline & PARANAPANEMA & Rio Paranapanema Energia S.A \\
\hline & CELPE & Cia Energética de Pernambuco \\
\hline & TERMOPE & Termopernambuco S.A \\
\hline \multirow{4}{*}{ Transmissão } & AFLUENTE T & Afluente Geração De Energia Elétrica S.A \\
\hline & CACHOEIRA & Cachoeira Paulista Transmissora Energia S.A \\
\hline & TRANS PAULIST & CTEEP Cia Transmissão Energia Elétrica Paulista \\
\hline & TAESA & Transmissora Aliança De Energia Elétrica S.A \\
\hline \multirow{20}{*}{ Distribuição } & CELPA & Centrais Elétricas do Pará S.A. \\
\hline & AMPLA & Ampla Energia E Serviços S.A. \\
\hline & CEMIG DIST & Cemig Distribuição S.A \\
\hline & COELBA & Cia Eletricidade Est. da Bahia \\
\hline & COELCE & Cia Energética do Ceara \\
\hline & CEMAR & Cia Energética do Maranhão \\
\hline & COSERN & Cia Energética Do Rio Gde Norte \\
\hline & CEED D & Cia Estadual de Distribuição de Energia Elétrica \\
\hline & PAUL LUZ & Cia Paulista de Força e Luz \\
\hline & CPFL PIRATIN & Cia Piratininga de Força e Luz \\
\hline & ESCELSA & EDP Espirito Santo Distribuição De Energia S.A \\
\hline & EBE & EDP São Paulo Distribuição De Energia S.A \\
\hline & ELEKTRO & Elektro Redes S.A \\
\hline & ELETROPAULO & Eletropaulo Metrop. Elet. São Paulo S.A \\
\hline & ENERGISA MT & Energisa Mato Grosso - Dist de Energia S.A. \\
\hline & ENERSUL & Energisa Mato Grosso Do Sul - Dist De Energia S.A. \\
\hline & LIGHT & Light Serviços de Eletricidade S.A \\
\hline & AES SUL & Rge Sul Distribuidora de Energia S.A \\
\hline & ENERGIAS BR & Edp - Energias do Brasil S.A \\
\hline & RIO GRANDE ENERGIA & Rio Grande Energia S.A \\
\hline \multirow{4}{*}{$\begin{array}{c}\text { Geração, Transmissão e } \\
\text { Distribuição }\end{array}$} & CEEE GT & Cia Estadual de Geração e Transmissão Energia Elétrica \\
\hline & STATKRAFT & Statkraft Energias Renovaveis S.A \\
\hline & CEMIG GT & Cemig Geração e Transmissão S.A \\
\hline & COPEL & Cia Paranaense de Energia \\
\hline
\end{tabular}

Fonte: Elaborado pelos autores, com base na B3 (2017). 
Observa-se na Figura 2 que na amostra selecionada há 15 empresas que tem como atividade principal geração de energia, quatro de transmissão, 20 de distribuição, três de geração e transmissão e uma que desenvolve as três atividades (Cia Paranaense de Energia - COPEL). Aqui se tratou num mesmo grupo as empresas com duas ou três atividades. Estas duas últimas foram agregadas para fins de análises, visto que a COPEL era a única empresa que tem como atividade principal as três operações.

0 presente estudo analisou as informações referentes ao reconhecimento, mensuração e evidenciação, conforme mostra a Figura 3, com base do CPC 04 R1 (2010).

Figura 3: Procedimentos para a verificação da comparabilidade conforme CPC 04 R1 (2010)

\begin{tabular}{|c|c|c|}
\hline Fases & Procedimentos & Itens \\
\hline Reconhecimento & Existência de ativo intangível & Identificar se possui ativo intangível \\
\hline \multirow{5}{*}{ Mensuração } & \multirow{2}{*}{ Método de avaliação } & Método do Custo \\
\hline & & Método do Valor justo \\
\hline & \multirow{2}{*}{ Teste de Recuperabilidade } & Identificar se faz o teste \\
\hline & & Se sim, houve perda? \\
\hline & Reavaliação dos ativos & No caso de ativos no exterior \\
\hline \multirow{17}{*}{ Evidenciação } & \multirow{7}{*}{ Ativos separados por classe } & Softwares \\
\hline & & Licenças e concessões \\
\hline & & Marcas \\
\hline & & Patentes \\
\hline & & Pesquisa e desenvolvimento \\
\hline & & Propriedade intelectual \\
\hline & & Ágio \\
\hline & \multirow{3}{*}{ Classificação da vida útil } & Vida útil definida \\
\hline & & Vida útil indefinida \\
\hline & & $\begin{array}{l}\text { Motivos para o intangível ser identificado como vida } \\
\text { útil indefinida }\end{array}$ \\
\hline & \multirow{5}{*}{ Amortização } & Amortização: Métodos e taxas de amortização \\
\hline & & Amortização: Vida útil estimada \\
\hline & & Amortização: Valor residual \\
\hline & & Amortização reconhecida no período \\
\hline & & Amortização acumuladas/ perdas \\
\hline & Valor do intangível no início do período & O valor no início do período \\
\hline & Valor do intangível ao final do período & O valor no final do período \\
\hline
\end{tabular}

Fonte: Elaborado pelos autores.

Foram analisados os itens que constam na Figura 3 , através de notas explicativas. A análise foi realizada e separada em: reconhecimento, mensuração e evidenciação. No reconhecimento foi analisada a existência de ativo intangível e verificado o seu valor. Na mensuração, investigou-se qual é o método que as empresas registram seus ativos intangíveis (valor de custo ou valor justo), se realizam o teste de recuperabilidade, se informam se houve perda ou não, e se realizam reavaliação de ativos. No quesito evidenciação, foi verificado se havia separação dos ativos por classe, a classificação da vida útil, dados referentes a amortização (métodos e taxas, vida útil estimada, valor residual, valor reconhecido no período, valor acumulado) e também o valor no início e no final do período.

Para análises e para alcançar os resultados do estudo, foram usadas algumas estatísticas descritivas, tais como média, máximo, mínimo, desvio padrão. Para verificar a comparabilidade das companhias brasileiras, foi utilizado o índice $\mathrm{H}$ (índice de Herfindahl), que tem como fórmula: 
Nível de comparabilidade dos ativos intangíveis das companhias brasileiras do segmento de energia elétrica listadas na B3.

$$
H=\sum_{k=1}^{M}(P i)^{2}
$$

Em que: Pi: frequência relativa de empresas do país que utiliza o método contábil $k$; e M: quantidade de métodos contábeis analisados.

$\mathrm{O}$ índice $\mathrm{H}$ pondera as frequências relativas de cada método contábil entre si, sendo a frequência relativa o quociente entre empresas optantes por determinado método e total de empresas. Seus valores variam entre 0 (zero) e 1 (um), na qual quanto mais próximo a um, maior a chance de escolher duas empresas aleatórias que utilizam o mesmo método.

Na presente pesquisa, a comparabilidade foi feita com a fase de mensuração, visto que os demais itens analisados na Figura 3 não se enquadram como uma escolha contábil.

\section{Análise dos Resultados}

\subsection{Reconhecimento}

Na Tabela 2, são demonstradas por ano quantas empresas possuem ativos intangíveis registradas em seus balanços patrimoniais.

Tabela 1: Distribuição das empresas por atividade

\begin{tabular}{l|c|c|c|c}
\multicolumn{1}{c|}{ Atividade } & $\mathbf{2 0 1 3}$ & $\mathbf{2 0 1 4}$ & $\mathbf{2 0 1 5}$ & $\mathbf{2 0 1 6}$ \\
\hline Geração & 12 & 12 & 13 & 13 \\
\hline Transmissão & 2 & 3 & 2 & 2 \\
\hline Distribuição & 20 & 19 & 19 & 19 \\
\hline Geração, transmissão e distribuição & 4 & 3 & 4 & 4 \\
\hline TOTAL & $\mathbf{3 8}$ & $\mathbf{3 7}$ & $\mathbf{3 8}$ & $\mathbf{3 8}$ \\
\hline
\end{tabular}

Fonte: Elaborado pelos autores.

As empresas Proman, Renova, Afluent T e Cachoeira não apresentam em nenhum dos anos estudados ativo intangível. A empresa CESP não apresenta nos anos de 2013 e 2014 e a empresa Rio Grande Energia não apresentou nos anos de 2014, 2015 e 2016. A atividade com maior expressividade no segmento elétrico listado na B3 é da atividade de distribuição, que representa nos anos cerca de $50 \%$.

\subsection{Mensuração}

A Tabela 3 demonstra as análises estatísticas descritivas do ativo intangível das empresas, por ano e por atividade. No ano de 2013 e 2014 a atividade que possui o maior ativo intangível é geração, já nos anos seguintes (2015 e 2016) é a de distribuição. Em todos os anos estudados, o menor valor de ativo intangível é apresentado por empresa de geração. Em relação a maior e menor média em todos os anos, tem-se aos segmentos de distribuição e transmissão, respectivamente. 
Ana Karoline Ventura, Juliane Pacheco \& Suliani Rover.

Referente à análise de desvio padrão, verifica-se que para o ano de 2013 e 2014 os valores mais discrepantes são em relação à atividade de geração, para os anos de 2015 e 2016 as empresas que possuem as três atividades. Em todos os anos a menor discrepância é da atividade de transmissão.

Tabela 3: Ativo intangível das empresas (em milhares de reais)

\begin{tabular}{|c|c|c|c|c|c|c|}
\hline Atividade & Ano & № Empresas & Média & Mínimo & Máximo & Desvio Padrão \\
\hline \multirow{4}{*}{ Geração } & 2016 & 12 & 869.606 & 23 & 3.171 .799 & 1.289 .233 \\
\hline & 2015 & 12 & 840.550 & 23 & 3.394 .429 & 1.321 .176 \\
\hline & 2014 & 11 & 1.469 .852 & 23 & 6.663 .157 & 2.221 .785 \\
\hline & 2013 & 12 & 1.317 .949 & 72 & 7.478 .425 & 2.269 .714 \\
\hline \multirow{4}{*}{ Transmissão } & 2016 & 2 & 33.505 & 25.166 & 41.843 & 11.792 \\
\hline & 2015 & 2 & 35.069 & 20.629 & 49.509 & 20.421 \\
\hline & 2014 & 2 & 34.661 & 13.300 & 56.022 & 30.209 \\
\hline & 2013 & 2 & 27.019 & 7.969 & 46.069 & 26.941 \\
\hline \multirow{4}{*}{ Distribuição } & 2016 & 19 & 2.671 .180 & 785.681 & 8.977 .637 & 2.269 .408 \\
\hline & 2015 & 19 & 2.288 .477 & 715.504 & 8.413 .168 & 1.865 .435 \\
\hline & 2014 & 19 & 1.729 .760 & 101.543 & 5.045 .454 & 1.233 .827 \\
\hline & 2013 & 20 & 1.972 .698 & 109.128 & 5.722 .928 & 1.307 .664 \\
\hline \multirow{4}{*}{$\begin{array}{c}\text { Geração, transmissão e } \\
\text { distribuição }\end{array}$} & 2016 & 4 & 1.637 .578 & 3.555 & 6.459 .812 & 3.214 .884 \\
\hline & 2015 & 4 & 1.594 .499 & 36.109 & 6.145 .076 & 3.033 .861 \\
\hline & 2014 & 4 & 612.473 & 50.396 & 2.174 .156 & 1.041 .540 \\
\hline & 2013 & 4 & 552.550 & 4.515 & 2.035.361 & 989.614 \\
\hline \multirow{4}{*}{ TOTAL } & 2016 & 37 & 1.832 .568 & 23 & 8.977 .637 & 2.192 .847 \\
\hline & 2015 & 37 & 1.622 .049 & 23 & 8.413 .168 & 1.902 .181 \\
\hline & 2014 & 36 & 1.432 .028 & 23 & 6.663 .157 & 1.588 .463 \\
\hline & 2013 & 38 & 1.514 .036 & 72 & 7.478 .425 & 1.683 .667 \\
\hline
\end{tabular}

Fonte: Elaborado pelos autores.

O Gráfico 1 apresenta a relação do ativo intangível pelo ativo total das empresas.

Gráfico 1: Relação ativo intangível e ativo total

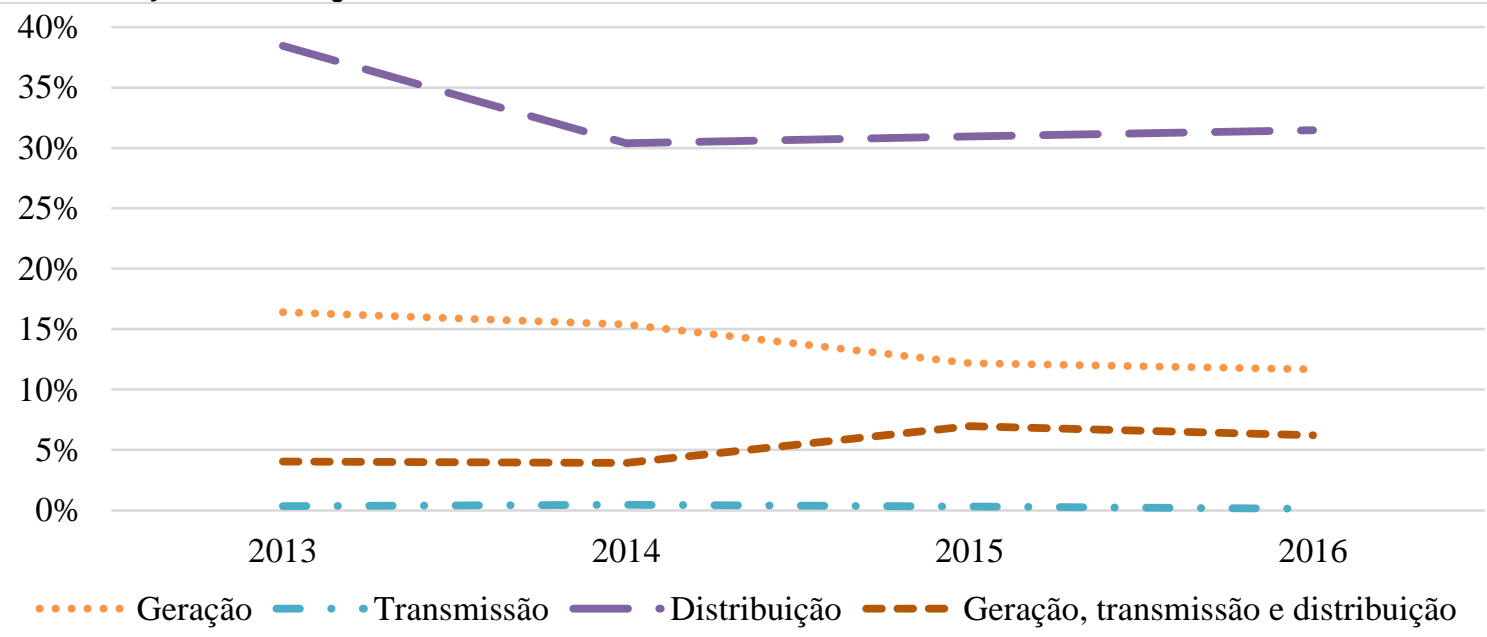

Fonte: Elaborado pelos autores. 
Como se pode observar no Gráfico 1, a atividade que possui uma maior proporção do ativo intangível com relação ao ativo total das empresas é a distribuição de energia, seguida pela geração. A atividade que 0 seu intangível em relação ao ativo total tem um nível de significância menor é a de transmissão, na qual nenhuma das empresas desta atividade possui $1 \%$ de representatividade. A queda da representatividade na atividade de Geração deu-se por conta da empresa AES Tietê que no ano de 2014 tinha 37,70\% de ativos intangíveis em relação ao ativo total e no ano de 2015 passou a ter 1,62\%. Isso ocorreu porque a empresa passou por uma reorganização societária e deixou de ter participações em outras sociedades.

\subsection{Evidenciação}

Conforme o primeiro procedimento de evidenciação foi analisado algumas classes de ativos intangíveis, sendo: software, licenças e concessões, marcas, patentes P\&D (Pesquisa e desenvolvimentos), capital intelectual, ágio e outros. $\mathrm{Na}$ Tabela 4 está representada a média das porcentagens das classes de ativos intangíveis que as empresas possuem.

Tabela 4: Relação entre classes com ativo intangível

\begin{tabular}{|c|c|c|c|c|c|c|}
\hline Atividade Principal & Ano & Softwares & $\begin{array}{l}\text { Licenças e } \\
\text { concessões }\end{array}$ & P\&D & Ágio & $\begin{array}{l}\text { Outros ativos } \\
\text { intangíveis }\end{array}$ \\
\hline \multirow{4}{*}{ Geração } & 2013 & $14,54 \%$ & $79,83 \%$ & $0,22 \%$ & $0,64 \%$ & $4,76 \%$ \\
\hline & 2014 & $5,77 \%$ & $88,05 \%$ & $5,02 \%$ & $0,73 \%$ & $0,42 \%$ \\
\hline & 2015 & $6,35 \%$ & $85,60 \%$ & $0,00 \%$ & $2,47 \%$ & $5,58 \%$ \\
\hline & 2016 & $6,69 \%$ & $88,27 \%$ & $0,00 \%$ & $1,22 \%$ & $3,82 \%$ \\
\hline \multirow{4}{*}{ Transmissão } & 2013 & $30,81 \%$ & $69,19 \%$ & $0,00 \%$ & $0,00 \%$ & $0,00 \%$ \\
\hline & 2014 & $46,67 \%$ & $53,33 \%$ & $0,00 \%$ & $0,00 \%$ & $0,00 \%$ \\
\hline & 2015 & $45,75 \%$ & $54,25 \%$ & $0,00 \%$ & $0,00 \%$ & $0,00 \%$ \\
\hline & 2016 & $43,54 \%$ & $56,46 \%$ & $0,00 \%$ & $0,00 \%$ & $0,00 \%$ \\
\hline \multirow{4}{*}{ Distribuição } & 2013 & $1,81 \%$ & $97,12 \%$ & $0,00 \%$ & $1,05 \%$ & $0,03 \%$ \\
\hline & 2014 & $4,13 \%$ & $90,21 \%$ & $0,00 \%$ & $5,58 \%$ & $0,07 \%$ \\
\hline & 2015 & $0,73 \%$ & $93,52 \%$ & $0,00 \%$ & $5,67 \%$ & $0,07 \%$ \\
\hline & 2016 & $1,08 \%$ & $93,69 \%$ & $0,00 \%$ & $5,10 \%$ & $0,12 \%$ \\
\hline \multirow{4}{*}{$\begin{array}{l}\text { Geração, transmissão, } \\
\text { distribuição }\end{array}$} & 2013 & $25,05 \%$ & $59,77 \%$ & $3,67 \%$ & $6,50 \%$ & $5,01 \%$ \\
\hline & 2014 & $25,14 \%$ & $60,07 \%$ & $0,00 \%$ & $8,79 \%$ & $5,99 \%$ \\
\hline & 2015 & $25,00 \%$ & $56,29 \%$ & $0,00 \%$ & $10,72 \%$ & $7,98 \%$ \\
\hline & 2016 & $25,00 \%$ & $64,10 \%$ & $0,00 \%$ & $1,73 \%$ & $9,17 \%$ \\
\hline \multirow{4}{*}{$\begin{array}{l}\text { ANÁLISE } \\
\text { GERAL }\end{array}$} & 2013 & $9,09 \%$ & $84,68 \%$ & $2,71 \%$ & $1,50 \%$ & $2,03 \%$ \\
\hline & 2014 & $8,46 \%$ & $84,79 \%$ & $1,52 \%$ & $4,33 \%$ & $0,89 \%$ \\
\hline & 2015 & $6,54 \%$ & $85,84 \%$ & $0,00 \%$ & $4,99 \%$ & $2,62 \%$ \\
\hline & 2016 & $6,63 \%$ & $87,76 \%$ & $0,00 \%$ & $3,40 \%$ & $2,21 \%$ \\
\hline
\end{tabular}

Fonte: Elaborado pelos autores.

Observou-se que marca, patente e capital intelectual não foram apresentadas no ativo intangível de nenhuma das empresas do estudo. No estudo existem empresas que possuem "outros ativos". Algumas dessas empresas colocam em notas o que compõe esses outros ativos, são itens como: transferência de material técnico, mão de obra ou capitalização de encargos, juros e capitalização de empréstimos.

Com as mudanças na legislação, as concessões se tornaram a classe com maior representatividade do intangível, conforme se pode observar na Tabela 4 em todos os anos e em todas as atividades. Inclusive para iniciar suas atividades, as empresas devem participar e vencer uma licitação e com isso ganhar uma 
concessão para atuar por até 35 anos, conforme regras da Agência Nacional de Energia Elétrica (ANEEL). Segundo 0 artigo 65 do Decreto $n^{0}$ 41.019, de 26 de fevereiro de 1957, diz que depende de concessão federal a exploração do serviço de energia elétrica quando a produção for maior que $150 \mathrm{kw}$, e as empresas de transmissão e de distribuição quando comercializem energia. A segunda classe com maior relevância é os softwares.

Os resultados da Tabela 4 contrariam os achados de Santos (2015), visto que o ágio foi um dos itens mais evidenciados, estando em 67 das 100 empresas pesquisas. Ressalta-se que Santos (2015) analisou as 100 maiores empresas da Revista Exame Melhores e Maiores de 2013, portanto abrangeu mais setores e segmentos que esta pesquisa. A Tabela 5 destaca por ano e por atividade que método que é realizado o registro dos ativos intangíveis nas empresas estudadas.

Tabela 5: Métodos de avaliação dos ativos

\begin{tabular}{|c|c|c|c|c|c|}
\hline Atividade & Tipo de avaliação & 2013 & 2014 & 2015 & 2016 \\
\hline \multirow{4}{*}{ Geração } & Valor de Custo & 9 & 8 & 9 & 9 \\
\hline & Valor Justo & 1 & 1 & 1 & 1 \\
\hline & Ambos & 2 & 2 & 2 & 2 \\
\hline & Não especifica & 0 & 1 & 1 & 1 \\
\hline \multirow{4}{*}{ Transmissão } & Valor de Custo & 1 & 1 & 1 & 1 \\
\hline & Valor Justo & 1 & 1 & 1 & 1 \\
\hline & Ambos & 0 & 0 & 0 & 0 \\
\hline & Não especifica & 0 & 0 & 0 & 0 \\
\hline \multirow{4}{*}{ Distribuição } & Valor de Custo & 14 & 14 & 14 & 14 \\
\hline & Valor Justo & 4 & 4 & 4 & 4 \\
\hline & Ambos & 2 & 2 & 2 & 2 \\
\hline & Não especifica & 0 & 0 & 0 & 0 \\
\hline \multirow{4}{*}{$\begin{array}{l}\text { Geração, transmissão e } \\
\text { distribuição }\end{array}$} & Valor de Custo & 2 & 2 & 2 & 2 \\
\hline & Valor Justo & 0 & 0 & 0 & 0 \\
\hline & Ambos & 2 & 2 & 2 & 2 \\
\hline & Não especifica & 0 & 0 & 0 & 0 \\
\hline \multirow{4}{*}{ TOTAL } & Valor de Custo & 26 & 25 & 26 & 26 \\
\hline & Valor Justo & 6 & 6 & 6 & 6 \\
\hline & Ambos & 6 & 6 & 6 & 6 \\
\hline & Não especifica & 0 & 1 & 1 & 1 \\
\hline
\end{tabular}

Fonte: Elaborado pelos autores.

Na Tabela 5 observar-se os métodos de avaliação dos ativos intangíveis, onde predomina o método de avaliação pelo valor de custo, seguido pelo valor justo com seis empresas e outras seis empresas avaliam seus ativos intangíveis pelos dois métodos.

Foi constatado também que nenhuma das empresas realizava a reavaliação de seus ativos, de modo que se encontram em consonância com a Lei $n^{0}$. 11.638/07, que passou a proibir a reavaliação de ativos no Brasil. Na Tabela 6 encontra-se a mensuração das empresas que fazem o teste de recuperabilidade, também conhecido como impairment test. 
Nível de comparabilidade dos ativos intangíveis das companhias brasileiras do segmento de energia elétrica listadas na B3.

Tabela 6: Teste de recuperabilidade

\begin{tabular}{|c|c|c|c|c|c|}
\hline Atividade & Teste de Recuperabilidade & 2013 & 2014 & 2015 & 2016 \\
\hline \multirow{3}{*}{ Geração } & Realiza & 7 & 5 & 7 & 6 \\
\hline & Não realiza & 1 & 1 & 1 & 1 \\
\hline & Não informa & 4 & 6 & 5 & 6 \\
\hline \multirow{3}{*}{ Transmissão } & Realiza & 1 & 1 & 1 & 1 \\
\hline & Não realiza & - & - & - & - \\
\hline & Não informa & 1 & 1 & 1 & 1 \\
\hline \multirow{3}{*}{ Distribuição } & Realiza & 18 & 16 & 14 & 15 \\
\hline & Não realiza & 2 & 3 & 2 & 3 \\
\hline & Não informa & - & 1 & 4 & 2 \\
\hline \multirow{3}{*}{$\begin{array}{c}\text { Geração, transmissão e } \\
\text { distribuição }\end{array}$} & Realiza & 4 & 4 & 4 & 4 \\
\hline & Não realiza & - & - & - & - \\
\hline & Não informa & - & - & - & - \\
\hline \multirow{3}{*}{ TOTAL } & Realiza & 30 & 26 & 26 & 26 \\
\hline & Não realiza & 3 & 4 & 3 & 4 \\
\hline & Não informa & 5 & 8 & 10 & 9 \\
\hline
\end{tabular}

Fonte: Elaborado pelos autores.

Na Tabela 6 pode-se observar que, no geral, aumentaram as empresas que não informam se realizam 0 teste. Das empresas que possuem as três operações todas realizam teste nos quatro anos pesquisados. Seguido das empresas de transmissão com $90 \%, 80 \%, 70 \%$ e $75 \%$ das empresas evidenciando o teste em 2013, 2014, 2015 e 2016, respectivamente. Das empresas que fizeram o teste em todos os anos, nove não informaram se houve perda ou não.

Todas as empresas que possuem ativos intangíveis em suas demonstrações possuem ativos com vida útil definida, devido às concessões de exploração de energia. O segmento de energia elétrica ainda conta com a contabilidade regulatória, na qual precisa fazer as demonstrações contábeis sob orientação da ANEEL. Em relação aos contatos de concessão, a ANEEL orienta às empresas do segmento que qualquer valor residual que seja apurado nos ativos intangíveis decorrentes da concessão, deve ser transferido para uma conta de Ativo Financeiro, o que não ocorre pela contabilidade societária. A Tabela 7 traz informações referentes à existência de ativos intangíveis com vida útil indefinida.

Tabela 7: Vida útil indefinida

\begin{tabular}{|c|c|c|c|c|c|}
\hline Atividade & Existência de vida útil indefinida & 2013 & 2014 & 2015 & 2017 \\
\hline \multirow{2}{*}{ Geração } & Não possui & 10 & 9 & 12 & 12 \\
\hline & Não especifica & 2 & 3 & 1 & 1 \\
\hline \multirow{2}{*}{ Transmissão } & Não possui & 0 & 0 & 0 & 0 \\
\hline & Não especifica & 2 & 2 & 2 & 2 \\
\hline \multirow{3}{*}{ Distribuição } & Possui & 1 & 1 & 1 & 1 \\
\hline & Não possui & 17 & 16 & 16 & 16 \\
\hline & Não especifica & 2 & 2 & 2 & 2 \\
\hline \multirow{2}{*}{$\begin{array}{l}\text { Geração, transmissão } \\
\text { e distribuição }\end{array}$} & Não possui & 2 & 2 & 2 & 2 \\
\hline & Não especifica & 2 & 2 & 2 & 2 \\
\hline \multirow{3}{*}{ TOTAL } & Possui & 1 & 1 & 1 & 1 \\
\hline & Não possui & 29 & 27 & 30 & 30 \\
\hline & Não especifica & 8 & 9 & 7 & 7 \\
\hline
\end{tabular}

Fonte: Elaborado pelos autores. 
$\mathrm{Na}$ Tabela 7, que mostra a existência de ativos intangíveis com vida útil indefinida, foi encontrada apenas a Cia Piratininga de Força e Luz uma empresa que especificava esse tipo de ativo.

O estudo analisou sobre amortização a evidenciação de métodos, taxas, vida útil estimada, valor residual, reconhecimento no período e amortização acumulada. Sobre métodos e taxas de amortização, foi observado ou que seguem taxas padrões da ANEEL, ou é calculado com base no padrão de consumo que terá até final da concessão. Em todos os anos estudados, duas empresas que tem como atividade principal a geração, não citaram em suas demonstrações contábeis os métodos ou taxas de amortização.

Todas as empresas, nos quatro anos estudados que possuem ativos intangíveis com vida útil definida, foram analisadas se informam seus ativos, qual a vida útil, e qual o valor residual. Uma empresa de geração, uma de transmissão e duas que são de geração, transmissão e distribuição, não informaram o valor residual e a vida útil estimada. As demais empresas que evidenciaram os ativos de vida útil definida, a vida é definida pelo tempo de concessão que a empresa resta. E o valor residual de todas as empresas que foram estudadas é zero, devido a apuração do valor residual ser transferido para o ativo financeiro.

Referente ao valor dos ativos intangíveis reconhecidos no período, no ano de 2013 duas empresas não divulgaram essa informação, sendo uma empresa de geração e uma de geração, transmissão e distribuição. Nos demais anos do estudo uma empresa de geração e uma de transmissão não evidenciaram o valor reconhecido.

Quando ao item analisado amortização acumulada, no ano de 2013 e 2014 oito empresas não divulgaram a informação (duas de cada atividade). No ano de 2015 e 2016 nove empresas não divulgaram (três de geração, duas de transmissão, duas de distribuição e duas de geração, transmissão e distribuição). Para demonstrar os resultados alcançados através das coletas, foi elaborado um ranking desconsiderando os itens que não se aplicam a empresa, onde o percentual de evidenciação foi calculado através da média dos quatro anos estudados, conforme mostra a Tabela 8.

Tabela 8: Ranking de evidenciação

\begin{tabular}{l|c|l|c}
\hline \multicolumn{1}{c|}{ EMPRESAS QUE MAIS EVIDENCIAM } & $\%$ & \multicolumn{1}{c|}{ EMPRESAS QUE MENOS EVIDENCIAM } & $\%$ \\
\hline CPFL Energias Renováveis S.A & $100 \%$ & Termopernambuco S.A & $0,0 \%$ \\
\hline Cia Energética de Pernambuco & $100 \%$ & Transmissora Aliança De Energia Elétrica S.A & $45,5 \%$ \\
\hline Cemig Distribuição S.A & $100 \%$ & Statkraft Energias Renováveis S.A & $63,6 \%$ \\
\hline Cia Eletricidade Est. Da Bahia & $100 \%$ & Cia Transmissão Energia Elétrica Paulista & $70,0 \%$ \\
\hline Cia Paulista de Força e Luz & $100 \%$ & Cia Estadual Ger.Trans.Ener.Elet & $72,7 \%$ \\
\hline Cia Piratininga de Força e Lux & $100 \%$ & Aes Tiete Energia S.A & $81,8 \%$ \\
\hline Elektro Redes S.A & $100 \%$ & Cia Estadual de distrib. Ener. Elet, & $81,8 \%$ \\
\hline Energisa Mato Grosso Dist De Energia & $100 \%$ & Rge Sul Distribuidora De Energia S.A & $81,8 \%$ \\
\hline Energisa Mato Grosso Do Sul S.A. & $100 \%$ & Cia Energética do Ceara & $87,5 \%$ \\
\hline Light Serviços De Eletricidade S.A & $100 \%$ & Edp São Paulo Distribuição De Energia S.A & $87,5 \%$ \\
\hline
\end{tabular}

Fonte: Elaborado pelos autores.

Foram elaboração do ranking de evidenciação foram considerados as dez que mais evidenciaram e as dez que menos evidenciaram, porém, 13 empresas evidenciaram tudo que foi analisado, de modo que foi utilizada a proporção do ativo intangível como critério de desempate, assim, foram eliminadas as empresas Engie, Paranapanema e Cemig GT.

Para ser possível analisar a comparabilidade das informações, foi utilizado 0 índice $\mathrm{H}$ nas escolhas contábeis analisadas no aspecto de mensuração nos itens método de avaliação e teste de recuperabilidade, conforme mostra na Tabela 9 . A reavaliação não foi analisada em virtude de não ter sido encontrada empresa de energia elétrica que a realizasse, respeitando a legislação brasileira. 
Nível de comparabilidade dos ativos intangíveis das companhias brasileiras do segmento de energia elétrica listadas na B3.

Tabela 9: Ranking de evidenciação

\begin{tabular}{|c|c|c|c|c|c|c|c|c|c|c|c|c|}
\hline \multirow[b]{2}{*}{ Mensuração Inicial } & \multicolumn{4}{|c|}{ Escolhas contábeis } & \multicolumn{4}{|c|}{ Frequência } & \multicolumn{4}{|c|}{$\mathrm{H}$} \\
\hline & 2013 & 2014 & 2015 & 2016 & 2013 & 2014 & 2015 & 2016 & 2013 & 2014 & 2015 & 2016 \\
\hline Custo de Aquisição & 26 & 25 & 26 & 26 & 0,684 & 0,657 & 0,666 & 0,666 & \multirow{4}{*}{0,518} & \multirow{4}{*}{0,483} & \multirow{4}{*}{0,492} & \multirow{4}{*}{0,492} \\
\hline Valor Justo & 6 & 6 & 6 & 6 & 0,157 & 0,157 & 0,153 & 0,153 & & & & \\
\hline Ambos & 6 & 6 & 6 & 6 & 0,157 & 0,157 & 0,153 & 0,153 & & & & \\
\hline Não mencionado & 0 & 1 & 1 & 1 & 0 & 0,026 & 0,025 & 0,025 & & & & \\
\hline Total de Empresas & 38 & 38 & 39 & 39 & 1 & 1 & 1 & 1 & 0,518 & 0,483 & 0,492 & 0,492 \\
\hline \multirow{2}{*}{$\begin{array}{l}\text { Teste de } \\
\text { recuperabilidade }\end{array}$} & \multicolumn{4}{|c|}{ Escolhas contábeis } & \multicolumn{4}{|c|}{ Frequência } & \multicolumn{4}{|c|}{$\mathrm{H}$} \\
\hline & 2013 & 2014 & 2015 & 2016 & 2013 & 2014 & 2015 & 2016 & 2013 & 2014 & 2015 & 2016 \\
\hline Teste Realizado & 30 & 26 & 26 & 26 & 0,789 & 0,684 & 0,666 & 0,666 & \multirow{3}{*}{0,646} & \multirow{3}{*}{0,523} & \multirow{3}{*}{0,516} & \multirow{3}{*}{0,508} \\
\hline Teste Não Realizado & 3 & 4 & 3 & 4 & 0,078 & 0,105 & 0,076 & 0,102 & & & & \\
\hline Não mencionado & 5 & 8 & 10 & 9 & 0,131 & 0,21 & 0,256 & 0,23 & & & & \\
\hline Total de Empresas & 38 & 38 & 39 & 39 & 1 & 1 & 1 & 1 & 0,646 & 0,523 & 0,516 & 0,508 \\
\hline
\end{tabular}

Fonte: Elaborado pelos autores.

$\mathrm{Na}$ Tabela 9 pode-se perceber que $\mathrm{o}$ índice $\mathrm{H}$ da escolha do método de mensuração é um valor aproximado e médio nos quatro anos do estudo. No ano de 2013 a chance de duas empresas diferentes escolherem o mesmo método de mensuração dos ativos intangíveis é de $51,8 \%$.

Quanto ao teste de recuperabilidade, o índice H é um pouco mais elevado no ano de 2013 onde as escolhas contábeis de empresas poderiam ser $64,6 \%$ iguais. Porém esse índice tem uma queda nos anos posteriores chegando em 50,8\% no ano de 2016.

Pode-se perceber, conforme o índice $\mathrm{H}$, que as companhias de energia elétrica, apesar de possuírem basicamente o mesmo item no intangível, as concessões, estão divididas quanto à mensuração inicial do seu intangível, de mesma forma ao realizar o teste de recuperabilidade, a probabilidade de escolher duas empresas que realizaram o teste ou não é de $50 \%$.

Por fim, algumas empresas do segmento apesar de possuírem intangíveis, não estão evidenciando as informações, visto que o menor e maior percentual de evidenciação foi de $0 \%$ e $100 \%$, respectivamente. Essa disparidade pode ter contribuído para o índice $\mathrm{H}$ médio encontrado. Conclui-se, portanto, que as companhias quanto a sua contabilidade societária, estão adotando critérios de mensuração e recuperabilidade similares, mas pela discrepância da evidenciação acabam tendo a comparabilidade prejudicada.

\section{Considerações Finais}

O estudo teve como objetivo verificar o nível de comparabilidade dos ativos intangíveis das empresas listados na B3 no período de 2013 a 2016. Para isso, realizou-se uma pesquisa de caráter descritivo com abordagem qualitativa e quantitativa. Utilizou-se uma amostra de 43 empresas do segmento de energia elétrica do Brasil, onde os dados necessários para a pesquisa foram analisados através de balanços patrimoniais e notas explicativas das empresas. A análise da pesquisa foi dividida nas etapas de reconhecimento, mensuração e evidenciação. Sobre reconhecimento foi verificado que cerca de $87 \%$ das empresas que compõe a amostra inicial reconheciam ativos intangíveis em seus balanços patrimoniais.

Com relação à mensuração foi identificado altas discrepâncias entre valores de ativos das empresas investigadas. 0 método de avaliação dos ativos que predomina é o valor de custo e, quanto ao teste de recuperabilidade, a maioria das empresas realiza anualmente. No que se refere à evidenciação dos ativos intangíveis, a classe dominante é a de licenças e concessões devido à característica do segmento. Além disso, 
praticamente todas as empresas apresentam ativo intangível com vida útil definida, com exceção de uma empresa que possui ativos com vida útil indefinida.

O cálculo do nível de comparabilidade foi realizado com base em dois quesitos referentes à mensuração: método de avaliação e teste de recuperabilidade. Foram identificados valores médios nos dois critérios, um pouco mais baixo nos métodos de avaliação de um ativo intangível do que no teste de recuperabilidade. Os resultados da pesquisa foram coerentes com os da pesquisa de Doni et al. (2016), Souza et al. (2016), Reina et al. (2014) e Tudor e Dragu (2010), que verificaram que o nível de comparabilidade das empresas estudadas é médio.

E contrapõe a pesquisa de Avelino et al. (2012) que apontou que nenhuma empresa apresenta em sua totalidade os critérios analisados. A presente pesquisa encontrou 13 empresas divulgam todos os itens investigados. Do mesmo modo, os autores constataram que a informação menos divulgada foi a de vida útil dos ativos, enquanto que a presente pesquisa verificou que quase cem por cento das empresas divulgam essa informação. Sugere-se para outras pesquisas um estudo com uma amostra maior de empresas abrangendo empresas abertas e fechadas de energia elétrica. E também uma pesquisa sobre os ativos financeiros dessas empresas, tal sugestão devido à peculiaridade desse item para o segmento.

\section{Referências}

Araújo, T., Souza, F., \& Lemes, S. (2015). O impacto das escolhas contábeis na comparabilidade das demonstrações financeiras de companhias abertas com programa de fidelização de clientes. Revista Reunir: Revista de Administração, Contabilidade e Sustentabilidade, 5(2), 43-61. doi: https://doi.org/10.18696/reunir.v5i2.273

Avelino, B. C., Pinheiro, L. E. T., \& Lamounier, W. M. (2012). Evidenciação de ativos intangíveis: estudo empírico em companhias abertas. Revista de Contabilidade e Organizações, 6(14), 22-45.

Carmo, C. H. S., Ribeiro, A. M., \& Carvalho, L. N. G. (2011). Convergência de fato ou de direito? A influência do sistema jurídico na aceitação das normas internacionais para pequenas e médias empresas. Revista Contabilidade \& Finanças, 22(57), $242-262$.

Coelho, L. V., Campagnoni, M., \& Rover, S. (2016, outubro). Nível de comparabilidade das práticas contábeis dos estoques de empresas do ramo vajerista listadas na BM\&FBOVESPA. Anais do Congresso de Iniciação Científica em Contabilidade da UFRGS, Porto Alegre, RS, Brasil, 1.

Comitê de Pronunciamentos Contábeis (2010). Pronunciamento Técnico CPC 04 R1, de 05 de novembro de 2010. Ativo intangível.

Comitê de Pronunciamentos Contábeis (2011). Pronunciamento Técnico CPC 00 R1, de 02 de dezembro de 2011. Estrutura Conceitual para Elaboração e Divulgação de Relatório Contábil - Financeiro.

Colauto, R. D.; Nascimento, P. S.; Avelino, B. C.; Bispo, O. N. A. (2009) Evidenciação de ativos intangíveis não adquiridos nos relatórios da administração das companhias listadas nos níveis de governança corporativa da Bovespa. Contabilidade Vista \& Revista, 20(1) 143-169.

Cole, V., Branson, J., \& Breesch, D. (2008). An analysis of methods to measure the comparability of the consolidated financial statements of the European listed companies from the viewpoint of user. Accountancy \& Bedrijfskunde, 28(3), 1-31.

Cole, V., Branson, J., \& Breesch, D. (2009). How to measure the comparability of financial statements?. International Journal of Managerial and Financial Accounting, 1(4), 379-397.

Decreto $n^{\circ} 8.671$ de 26 de fevereiro de 1957. (1957). Regulamenta os serviços de energia elétrica. Diário Oficial da União, Rio de Janeiro.

Doni, F., Taplin, R. H., \& Verona, R. (2016). Comparability of company accounts using IFRS and US GAAP: Empirical evidence of European and US Financial Statements. International Journal of Business and Management, 11(12), 54-76.

Eckert, A., Mecca, M., Biasio, R., \& Souza, K. (2012). Normas contábeis de reconhecimento e mensuração do ativo imobilizado: impacto em empresas de bens industriais gaúchas listadas na BM\&FBovespa. Revista Contabilidade e Controladoria, 4(2). doi: http://dx.doi.org/10.5380/rcc.v4i2.26574

Ferreira, G. D., Carmo, C. H. S., Moura, P. J. P., \& Ribeiro, A. M. (2017, Julho). Value Relevance de Ativos Intangíveis: Uma Análise nas Empresas do Setor de Energia Elétrica da Bolsa Brasileira. Anais USP International Conference In Accounting, São Paulo, SP, Brasil, 17. 


\section{Nível de comparabilidade dos ativos intangíveis das companhias brasileiras do segmento de energia elétrica listadas na B3.}

Franco, G., Kothari, S. P., \& Verdi, R. S. (2011). The benefits of financial statement comparability. Journal of Accounting Research, 49(4), 895-931.

Høegh-Krohn, N. E. J., \& Knivsflå, K. H. (2000). Accounting for intangible assets in Scandinavia, the UK, the US, and by the IASC: Challenges and a solution. The International Journal of Accounting, 35(2), 243-265.

IFRS Foundation (2017). Pocket Guide to IFRS® Standards: the global financial reporting language. 216.

Lei n. 6.404 de 15 de dezembro de 1976. (1976). Sociedades por ações. Diário Oficial da União, Brasília.

Lei n. 11.638 de 28 de dezembro de 2007. (2007). Altera e revoga dispositivos da Lei no 6.404, de 15 de dezembro de 1976, e da Lei no 6.385 , de 7 de dezembro de 1976, e estende às sociedades de grande porte disposições relativas à elaboração e divulgação de demonstrações financeiras. Diário Oficial da União, Brasília.

Lei n. 11.941 de 27 de maio de 2009. (2009). Altera a legislação tributária federal relativa ao parcelamento ordinário de débitos tributários; concede remissão nos casos em que especifica; institui regime tributário de transição, alterando o Decreto n० 70.235 , de 6 de março de 1972, as Leis nos 8.212, de 24 de julho de 1991, 8.213, de 24 de julho de 1991, 8.218, de 29 de agosto de 1991, 9.249, de 26 de dezembro de 1995, 9.430, de 27 de dezembro de 1996, 9.469, de 10 de julho de 1997, 9.532, de 10 de dezembro de 1997, 10.426, de 24 de abril de 2002, 10.480, de 2 de julho de 2002, 10.522, de 19 de julho de 2002, 10.887, de 18 de junho de 2004, e 6.404, de 15 de dezembro de 1976, o Decreto-Lei no 1.598, de 26 de dezembro de 1977, e as Leis nos 8.981 , de 20 de janeiro de 1995, 10.925, de 23 de julho de 2004, 10.637, de 30 de dezembro de 2002, 10.833, de 29 de dezembro de 2003, 11.116, de 18 de maio de 2005, 11.732, de 30 de junho de 2008, 10.260, de 12 de julho de 2001, 9.873, de 23 de novembro de 1999, 11.171, de 2 de setembro de 2005, 11.345, de 14 de setembro de 2006; prorroga a vigência da Lei no 8.989 , de 24 de fevereiro de 1995; revoga dispositivos das Leis nos 8.383, de 30 de dezembro de 1991, e 8.620, de 5 de janeiro de 1993, do Decreto-Lei no 73, de 21 de novembro de 1966, das Leis nos 10.190, de 14 de fevereiro de 2001, 9.718, de 27 de novembro de 1998, e 6.938, de 31 de agosto de 1981, 9.964, de 10 de abril de 2000, e, a partir da instalação do Conselho Administrativo de Recursos Fiscais, os Decretos nos 83.304, de 28 de março de 1979, e 89.892, de 2 de julho de 1984, e o art. 112 da Lei no 11.196, de 21 de novembro de 2005; e dá outras providências. Diário Oficial da União, Brasília.

Kayo, E., Kimura, H., Martin, D., \& Nakamura, W. (2006). Ativos intangíveis, ciclo de vida e criação de valor. Revista de Administração Contemporânea, 10(3), 73-90. doi: https://doi.org/10.1590/S1415-65552006000300005

Kloeppel, N.; Klann, R. C.; Zittei, M. V. M. (2013). Ativos intangíveis: reconhecimento em empresas de utilidade publica listadas na BM\&FBovespa. Revista de Estudos Contábeis, 4(7), 98-115.

Kohler, E. L. (1957). Dictionary for accountants. New York: Prentice-Hall.

Moura, G. D., Fank, O. L., \& Varela, P. S. (2012). Evidenciação dos ativos intangíveis pelas empresas do setor de energia elétrica listadas na BM\&FBOVESPA. Contabilidade, Gestão e Governança, 15(1), 17-32.

Perez, M. M.; Famá, R. (2016). Ativos intangíveis e o desempenho empresarial. Revista Contabilidade \& Finanças, 17(40), 07-24.

Reina, D. R. M., Reina, D., \& Silva, S. F. (2014). Comparabilidade da informação contábil em empresas brasileiras após a adoção das normas internacionais de contabilidade. Revista Contemporânea de Contabilidade, 11(23), 77-94.

Santos, J. (2015). Evidências dos ativos intangíveis no contexto brasileiro: representatividade, caracterização, percepção de mercado e desempenho. Revista Contabilidade e Controladoria, 7(3). doi: http://dx.doi.org/10.5380/rcc.v7i3.38931

Souza, F. Ê. A., Botinha, R. A., \& Lemes, S. (2016). A Comparabilidade das escolhas contábeis na mensuração de ativos intangíveis de companhias abertas brasileiras e portuguesas. RACE: Revista de Administração, Contabilidade e Economia, 15(3), $1117-1142$.

Scalzer, R. S. (2013, julho). A adoção do ICPC01 e os impactos nas demonstrações contábeis: um estudo de caso na Light SESA. Anais do Congresso USP - Controladoria e Contabilidade, São Paulo, SP, Brasil, 13.

Souza, F. Ê. A., \& Lemes, S. (2016). A comparabilidade das escolhas contábeis na mensuração subsequente de ativos imobilizados, de ativos intangíveis e de propriedades para investimento em empresas da América do Sul. Revista Contabilidade \& Finanças, 27(71), 169-184. Epub May 20, 2016. doi: https://dx.doi.org/10.1590/1808-057x201501480

Taplin, R. H. (2004). A unified approach to the measurement of international accounting harmony. Accounting and Business Research, 34(1), 57-73.

Tavares, A. L., Gonçalves, R. S., \& Niyama, J. K. (2010). Heritage assets: uma análise comparativa das normas emanadas do FASB, ASB e CFC. ASAA - Advances in Scientific and Applied Accounting, 3(1), 65-89.

Tudor, A. T., \& Dragu, I. M. (2010). Impact of International Financial Reporting Standards on accounting practices harmonization within European Union-particular case of intangible assets. Annales Universitatis Apulensis: Series Oeconomica, 12(1), 191-206.

Van der Tas, L. G. (1988). Measuring harmonisation of financial reporting practice. Accounting and business research, 18(70), 157169. 


\section{DADOS DAS AUTORAS}

\section{Ana Karoline Ventura}

Bacharela em Ciências Contábeis na Universidade Federal de Santa Catarina

Endereço: Rua Eng. Agronômico Andrei Cristian Ferreira, s/n, Trindade

CEP: 88040-900 - Florianópolis/SC - Brasil

E-mail: anakventura@gmail.com

Telefone: (48) 99642-1736

\section{Juliane Pacheco}

Mestre em Contabilidade pelo Programa de Pós-Graduação em Contabilidade na UFSC.

Doutoranda em Contabilidade pelo Programa de Pós-Graduação em Contabilidade na UFSC.

Endereço: Rua Eng. Agronômico Andrei Cristian Ferreira, s/n, Trindade

CEP: 88040-900 - Florianópolis/SC - Brasil

E-mail: pac.juliane@gmail.com

Telefone: (48) 98826-4799

\section{Suliani Rover}

Doutora em Controladoria e Contabilidade pela Universidade de São Paulo

Professora do Departamento de Ciências Contábeis e do Programa de Pós-Graduação em Contabilidade (PPGC) da Universidade Federal de Santa Catarina (UFSC).

Endereço: Rua Eng. Agronômico Andrei Cristian Ferreira, s/n, Trindade

CEP: 88040-900 - Florianópolis/SC - Brasil

E-mail: sulianirover@gmail.com

Telefone: (48) 3721-3892

\section{Contribuição das Autoras:}

\begin{tabular}{lccc}
\hline Contribuição & $\begin{array}{c}\text { Ana Karoline } \\
\text { Ventura }\end{array}$ & $\begin{array}{c}\text { Juliane } \\
\text { Pacheco }\end{array}$ & $\begin{array}{c}\text { Suliani } \\
\text { Rover }\end{array}$ \\
\hline 1. Concepção do assunto e tema da pesquisa & $\sqrt{ }$ & & $\sqrt{ }$ \\
2. Definição do problema de pesquisa & $\sqrt{ }$ & & $\sqrt{ }$ \\
3. Desenvolvimento das hipóteses e constructos da & $\sqrt{ }$ & & \\
pesquisa (trabalhos teórico-empíricos) & & $\sqrt{ }$ \\
4. Desenvolvimento das proposições teóricas & & & $\sqrt{ }$ \\
(trabalhos teóricos os ensaios teóricos) & $\sqrt{ }$ & \\
5. Desenvolvimento da plataforma teórica & $\sqrt{ }$ & $\sqrt{ }$ \\
6. Delineamento dos procedimentos metodológicos & $\sqrt{ }$ & $\sqrt{ }$ \\
7. Processo de coleta de dados & $\sqrt{ }$ & $\sqrt{ }$ \\
8. Análises estatísticas & $\sqrt{ }$ & $\sqrt{ }$ \\
9. Análises e interpretações dos dados coletados & $\sqrt{ }$ & $\sqrt{ }$ \\
10. Considerações finais ou conclusões da pesquisa & & $\sqrt{ }$ \\
11. Revisão crítica do manuscrito & $\sqrt{ }$ & \\
12. Redação do manuscrito & & & \\
\hline
\end{tabular}

